\begin{tabular}{|c|c|c|}
\hline \multicolumn{3}{|c|}{ Colorectal polyps $\leq 10 \mathrm{~mm}(\mathrm{~N}=370) 95 \% \mathrm{Cl}$} \\
\hline Accuracy & $91.8 \%$ & $89.11 \%$ to $95.17 \%$ \\
\hline Sensitivity & $96.8 \%$ & $93.94 \%$ to $98.64 \%$ \\
\hline Specificity & $75.8 \%$ & $63.64 \%$ to $85.46 \%$ \\
\hline NPV & $86.2 \%$ & $75.71 \%$ to $92.61 \%$ \\
\hline \multicolumn{3}{|c|}{ Colorectal polyps $\leq 5 \mathrm{~mm}(\mathrm{~N}=280)$} \\
\hline Accuracy & $89.3 \%$ & $85.68 \%$ to $92.29 \%$ \\
\hline Sensitivity & $94.2 \%$ & $90.66 \%$ to $96.74 \%$ \\
\hline Specificity & $77.1 \%$ & $67.93 \%$ to $84.77 \%$ \\
\hline NPV & $84.4 \%$ & $76.57 \%$ to $89.92 \%$ \\
\hline \multicolumn{3}{|c|}{ Recto-sigmoid polyps $\leq 5 \mathrm{~mm}(\mathrm{~N}=131)$} \\
\hline Accuracy & $89.5 \%$ & $85.57 \%$ to $91.16 \%$ \\
\hline Sensitivity & $95.8 \%$ & $92.47 \%$ to $97.98 \%$ \\
\hline Specificity & $78.2 \%$ & $68.72 \%$ to $83.86 \%$ \\
\hline NPV & $90.9 \%$ & $84.40 \%$ to $94.87 \%$ \\
\hline
\end{tabular}

Conclusion Real time optical diagnosis in trained endoscopists using WL and BLI along with BASIC meets PIVI criteria for diminutive rectosigmoid polyps.

\section{PTU-32 NATURAL LANGUAGE PROCESSING DRIVEN COMPARISON OF SMALL BOWEL MRI AND CAPSULE ENDOSCOPY REPORTING FOR CROHN'S}

\footnotetext{
${ }^{1,2}$ Matthew Stammers, ${ }^{2}$ Hang Phan, ${ }^{1,2}$ Florina Borca, ${ }^{1}$ Bilal Khurshid, ${ }^{1}$ Moeed Minto, ${ }^{1}$ Sohail Rahmany, ${ }^{1}$ Srishti Sarkar, ${ }^{1,2}$ Robert Livingstone*, ${ }^{1}$ Esther Hawkes, ${ }^{1}$ Imdadur Rahman, 'Markus Gwiggner. 'University Hospital Southampton, Southampton, UK; ${ }^{2}$ Clinical Informatics Research Unit (CIRU), Southampton, UK
}

\subsection{6/gutjnl-2021-BSG.105}

Introduction Small Bowel Capsule Endoscopy (SBCE) has an established role in the diagnosis/management of small bowel Crohn's disease (CD). Previous work has suggested its diagnostic yield is comparable to that of Small Bowel MRI (SBMR), but the narrative nature of reporting makes this challenging to evaluate formally.

Methods Anonymised data from the electronic health record were systematically extracted from patients undergoing SBCE at our hospital between Jan 2016- Jan 2020 and categorised according to indication. A subgroup with suspected or established Crohn's disease was identified, and corresponding SBMR and calprotectin results were obtained. Natural

\begin{tabular}{|c|c|c|c|c|c|}
\hline $\begin{array}{l}\text { Small } \\
\text { Bowel } \\
\text { Test }\end{array}$ & $\begin{array}{l}\text { 'Crohn's' } \\
\text { mentioned } \\
\text { as the } \\
\text { potential } \\
\text { diagnosis }\end{array}$ & $\begin{array}{l}\text { A positive finding } \\
\text { of small bowel } \\
\text { 'inflammation/ } \\
\text { ulceration' } \\
\text { described }\end{array}$ & $\begin{array}{l}\text { A positive } \\
\text { finding of } \\
\text { a } \\
\text { 'stricture' } \\
\text { described }\end{array}$ & $\begin{array}{l}\text { Terms of } \\
\text { uncertainty } \\
\text { used in } \\
\text { report } \\
\text { conclusion }\end{array}$ & $\begin{array}{l}\text { A positive } \\
\text { finding of } \\
\text { 'thickening' } \\
\text { described }\end{array}$ \\
\hline SBMR & $3.75 \%(n=5)$ & $6.02 \%(n=8)$ & $3.01 \%(n=4)$ & $\begin{array}{l}11.28 \% \\
(n=15)\end{array}$ & $6.77 \%(n=9)$ \\
\hline SBCE & $\begin{array}{l}14.29 \% \\
(n=19)\end{array}$ & $17.29 \%(n=23)$ & $3.76 \%(n=5)$ & $2.26 \%(n=3)$ & $0.75 \%(n=1)$ \\
\hline$\chi^{2} \& p$ & $\begin{array}{l}8.98 \\
(p=0.003)\end{array}$ & $8.22(p=0.004)$ & $\begin{array}{l}0.12 \\
(p=0.115)\end{array}$ & $\begin{array}{l}8.58 \\
(p=0.003)\end{array}$ & $\begin{array}{l}6.65 \\
(p=0.009)\end{array}$ \\
\hline
\end{tabular}

language processing (NLP) techniques were used to compare the content and diagnostic accuracy of the reports.

Results Out of 1016 patients undergoing SBCE, 494 patients were suspected as having small bowel CD. Of this cohort, 133 underwent SBCE within 180 days of SBMR. 59 patients had corresponding faecal calprotectin (FC) measured (Mean: $318.12+/-138.39$ ).

Tokenisation demonstrated that the style and content of the SBCE vs SBMR reports were very different in form and structure. The resultant 'word-bags' revealed that SBCE reports had significantly more 'diagnostic' weight, as described in Table 1:

Mean FC was significantly higher in patients with the term 'ulceration' reported on SBCE $(703.5+/-353)$ compared to 'no ulceration' $(265.2+/-148.38)$ ( $p=0.044)$ linking the word 'ulceration' with more severe disease descriptions.

Conclusions NLP is a powerful novel tool to compare narrative diagnostic accuracy between SBCE and SBMR not previously described. FC is positively correlated with small bowel 'ulceration' linking descriptive, diagnostic terms to biomarkers. According to our results, SBCE alone rather than SBMR is necessary to investigate small bowel Crohn's disease unless full-thickness stricturing is suspected from clinical symptoms.

\section{PTU-33 DUODENAL INSPECTION DURING GASTROSCOPY; SHOULD THERE BE AN EXEMPTION IN THIS 'STANDARD' FOR BARRETT'S SURVEILLANCE?}

Andrew King*, David Nylander, Clare Parker. Newcastle Upon Tyne NHS Trust, Newcastle Upon Tyne, UK

\subsection{6/gutjnl-2021-BSG.106}

Introduction Current British Society of Gastroenterology (BSG) guidance recommends that Barrett's surveillance should adhere to a quadrantic $2 \mathrm{~cm}$ biopsy protocol, in addition to sampling any visible lesions (Seattle Biopsy Protocol - SBP) ${ }^{1}$. This, together with photographic evidence of intubation of second part of duodenum (D2), are part of the BSG measurable standards for gastroscopy (OGD) ${ }^{2}$.

In long Barrett's segments, OGD can be prolonged and uncomfortable for patients, especially as the majority are performed with anaesthetic throat spray and/or light sedation, which may affect endoscopist compliance with SBP.

We postulated that if endoscopists could be reassured that D2 intubation and examination did not alter management, then they would spend more time on careful oesophageal inspection and adherence to the SBP.

Therefore, we planned our audit to assess:

5. If adherence to SBP was affected by maximal length of Barrett's a) Occurrence of dysplasia and neoplasia b) If duodenal findings led to a change in management

Methods All patients undergoing Barrett's surveillance at Newcastle upon Tyne (an upper GI cancer referral centre) and South Tyneside Hospitals in North East UK between from 01/ $04 / 18$ to $31 / 03 / 19$ were identified. Their current and previous OGD reports were reviewed to determine demographics, Barrett's length, adherence to SBP, histology and duodenal findings.

Results A total of 1335 endoscopy reports were reviewed from 390 patients occurring between January 2008 and April 2020. $282(72 \%)$ were males, with an average age of at 